\title{
Brain and spinal cord MRI in motor neuron disease
}

\author{
J W Thorpe, I F Moseley, C H Hawkes, D G MacManus, W I McDonald, D H Miller
}

\begin{abstract}
Motor neuron disease causes widespread degeneration of motor neurons within both the brain and spinal cord. Brain and spinal cord MRI were performed in 11 patients with motor neuron disease, and in 17 controls. Symmetric areas of high signal within the corticospinal tracts were found in nine patients on $T 2$ weighted spin echo (SE) or fast spin echo (FSE) images of the brain and in eight on $\mathrm{T} 2$ or T2* weighed images of the spinal cord. High signal within the posterior limbs of the internal capsules was also found in four controls; this finding in isolation is therefore not pathological. No controls had abnormalities within the spinal cord. Low signal within the motor cortex was found in 10 patients, but was also seen in six controls. Thus MRI often displays characteristic abnormalities within the corticospinal tracts in patients with motor neuron disease, and should be considered in the investigation of suspected cases.
\end{abstract}

(F Neurol Neorosurg Psychiatry 1996;61:314-317)

Keywords: magnetic resonance imaging; motor neuron disease

Motor neuron disease is characterised by progressive degeneration of upper and lower motor neurons throughout the CNS. The main role of MRI in the diagnosis of motor neuron disease has been to exclude other causes of bulbar or limb weakness, such as multiple sclerosis and compressive lesions at the foramen magnum or affecting the spinal cord. However, various brain abnormalities on MRI have been reported in motor neuron disease. High signal within the corticospinal tracts, especially the posterior limbs of the internal capsules, has been described on T2 weighted images ${ }^{1-7}$; one study records low signal in the precentral gyrus, tentatively ascribed to excess iron deposition within the degenerating motor cortex, ${ }^{5}$ and another multiple discrete white matter lesions. ${ }^{8}$

Pathological studies in motor neuron disease have disclosed degeneration of motor neurons throughout the corticospinal tracts ${ }^{9-12}$; the spinal cord is often involved more exten- sively than the brain. The lateral corticospinal tracts are primarily affected but other tracts, including the anterior corticospinal tracts and the posterior columns, may be involved. Despite such extensive pathological involvement, there is a paucity of MRI reports of spinal cord abnormalities. Sales Luís et $a l^{2}$ showed signal change extending as far as the spinal cord on coronal images of the brain in two of 20 patients. Friedman and Tartaglino ${ }^{6}$ reported one patient in whom high signal was visible within the anterior and lateral columns of the cervical cord on axial T2 weighted images. We report the MRI findings in both the brain and spinal cord of 11 patients with motor neuron disease.

\section{Patients and methods}

We studied 11 patients (six men and five women) aged 34 to 65 (mean 50) years. All gave written informed consent. In two, with purely upper motor neuron signs and no EMG evidence of denervation, the clinical picture was consistent with primary lateral sclerosis, ${ }^{4}$ whereas the others had typical motor neuron disease.

A 1.5 T imager was used for MRI. T2 weighted axial images of the brain were acquired in all cases. In three patients spin echo (SE) and in eight fast spin echo (FSE) images were obtained. Typical parameters were $\mathrm{FSE}_{2900 / 20,100}$ (echo train length (ETL) 8) or $\mathrm{SE}_{2700 / 32,80}, 24 \mathrm{~cm}$ field of view (FOV), one excitation; $4 \mathrm{~mm}$ contiguous interleaved slices and a $256 \times 256$ matrix were generally used for FSE images, with $5 \mathrm{~mm}$ slices with a $2.5 \mathrm{~mm}$ interslice gap and a $192 \times 256$ matrix for SE. In seven patients heavily T2 weighted fluid attenuated inversion recovery (FLAIR) images ( IR $_{6000 / 2000 / 140}, 8 \mathrm{~mm}$ slices, $128 \times 256$ matrix, 0.75 excitations) were also obtained. Spinal cord images were acquired with a spinal multiarray coil. Sagittal T1 weighted $\mathrm{SE}$ ( $\mathrm{SE}_{570 / 19}, 4 \mathrm{~mm}$ contiguous interleaved slices, $256 \times 512$ matrix, $48 \mathrm{~cm}$ FOV, one excitation) and T2 weighted FSE images (FSE ${ }_{2500 / 51 \text { and } 102}, 3 \mathrm{~mm}$ contiguous interleaved slices, $512 \times 512$ matrix, ETL $16,48 \mathrm{~cm}$ FOV, two excitations) of the whole spinal cord were obtained. Axial $\mathrm{T} 2{ }^{\star}$ weighted gradient echo images were then acquired through the cervical cord. The image parameters were 


\begin{tabular}{|c|c|c|c|c|c|c|c|c|c|c|c|c|c|c|c|c|c|c|}
\hline \multirow[b]{3}{*}{$\begin{array}{l}\text { Patient } \\
\text { No }\end{array}$} & \multirow{2}{*}{\multicolumn{7}{|c|}{ Clinical }} & \multicolumn{8}{|c|}{ Brain $M R I$} & \multirow{2}{*}{\multicolumn{3}{|c|}{ Cord MRI }} \\
\hline & & & & & & & & $H S$ & & & & & & & & & & \\
\hline & $\begin{array}{l}\text { Age } \\
(y)\end{array}$ & Sex & $\begin{array}{l}\text { Duration } \\
\text { (months) }\end{array}$ & $\begin{array}{l}\text { Initial } \\
\text { symptoms }\end{array}$ & $\begin{array}{l}\text { UMgnN } \\
\text { signs }\end{array}$ & $\begin{array}{l}\text { LMN } \\
\text { signs }\end{array}$ & $\begin{array}{l}\text { Bulbar } \\
\text { signs }\end{array}$ & $C$ & $C S$ & $I C$ & $C P$ & $P$ & $M P$ & $L S$ & $F L A I R$ & Def & Prob & Poss \\
\hline $\begin{array}{r}1 \\
2 \\
3 \\
4 \\
5 \\
6 \\
7 \\
8 \\
9 \\
10 \\
11\end{array}$ & $\begin{array}{l}47 \\
34 \\
51 \\
52 \\
58 \\
45 \\
39 \\
41 \\
65 \\
61 \\
60\end{array}$ & $\begin{array}{l}M \\
M \\
M \\
M \\
F \\
F \\
F \\
F \\
M \\
M \\
F\end{array}$ & \begin{tabular}{r|r|}
36 \\
4 \\
22 \\
24 \\
49 \\
24 \\
6 \\
48 \\
48 \\
11 \\
7 \\
26
\end{tabular} & $\begin{array}{l}\text { Weak L hand } \\
\text { Weak hands } \\
\text { Weak L leg } \\
\text { R foot drop } \\
\text { L foot drop } \\
\text { Weak R hand } \\
\text { Stiff R leg } \\
\text { Weak L hand } \\
\text { Weak L leg } \\
\text { Dysphagia } \\
\text { L foot drop }\end{array}$ & $\begin{array}{l}+ \\
+ \\
+ \\
+ \\
+ \\
+ \\
+ \\
+ \\
+ \\
+ \\
+\end{array}$ & $\begin{array}{l}- \\
+ \\
+ \\
+ \\
+ \\
- \\
+ \\
+ \\
+ \\
+ \\
+\end{array}$ & $\begin{array}{l}+ \\
- \\
- \\
- \\
+ \\
- \\
- \\
+ \\
+\end{array}$ & $\begin{array}{l}- \\
++ \\
+ \\
- \\
- \\
+ \\
++ \\
+ \\
-\end{array}$ & $\begin{array}{l}- \\
++ \\
+ \\
+ \\
- \\
+ \\
+ \\
++ \\
+ \\
+ \\
-\end{array}$ & $\begin{array}{l}+ \\
++ \\
+ \\
++ \\
+ \\
+ \\
+ \\
++ \\
+ \\
+ \\
+\end{array}$ & $\begin{array}{l}+ \\
++ \\
+ \\
++ \\
- \\
+ \\
+ \\
++ \\
- \\
- \\
-\end{array}$ & $\begin{array}{l}- \\
- \\
- \\
+ \\
- \\
+ \\
++ \\
+ \\
-\end{array}$ & $\begin{array}{l}- \\
+ \\
- \\
- \\
- \\
+ \\
+ \\
- \\
- \\
-\end{array}$ & $\begin{array}{l}+(+a \\
(+) a \\
+(a+b) \\
+(a) \\
- \\
+(a+b) \\
++(a) \\
+(a+b) \\
+(a) \\
+(a) \\
+(a)\end{array}$ & $\begin{array}{l}- \\
+ \\
- \\
+ \\
\text { ND } \\
- \\
+ \\
\text { ND } \\
\text { ND } \\
\text { ND } \\
-\end{array}$ & $\begin{array}{l}2 \\
3 \\
0 \\
3 \\
0 \\
3 \\
3 \\
3 \\
0 \\
0 \\
0\end{array}$ & $\begin{array}{l}0 \\
0 \\
0 \\
0 \\
0 \\
0 \\
0 \\
0 \\
1 \\
0 \\
2\end{array}$ & $\begin{array}{l}0 \\
0 \\
2 \\
0 \\
0 \\
0 \\
0 \\
0 \\
0 \\
0 \\
0\end{array}$ \\
\hline
\end{tabular}

LS = low signal; (a) = in precentral cortex; (b) = in postcentral gyrus; HS = high signal; C = cortex; CS = centrum semiovale; IC = internal capsules; CP = cerebral peduncles; $\mathrm{P}=$ pons; $\mathrm{MP}=$ medullary pyramids. $+=$ Abnormalities present; $++=$ pronounced abnormalities; $-=$ normal; ND $=$ not done. Spinal cord $\mathrm{MRI} 0=$ no HS; $1=$ HS on one slice only; $2=$ HS on more than one slice; $3=$ HS throughout cervical cord. Def $=$ definite; Prob $=$ probable; Poss $=$ possible.

Figure 1 Patient 2: axial T2 weighted FSE image of the brain showing marked high signal (arrowed): (a) in the centrum semiovale. (b) within the posterio limbs of the internal capsule; (c) within the cerebral peduncles.
$\mathrm{GE}_{400 / 30}$, flip angle $=12^{\circ}, 5 \mathrm{~mm}$ slices, $256 \times 256$ matrix, $20 \mathrm{~cm}$ FOV, one excitation. In one patient sagittal and axial T2 weighted SE images were obtained instead; in this case axial images of the thoracic cord were also collected.

We also performed MRI in 17 unaffected controls (16 healthy volunteers and one patient with a myopathy): 11 (six men and five women, aged 36 to 70 , mean 51 years) underwent T2 weighted FSE imaging of the brain
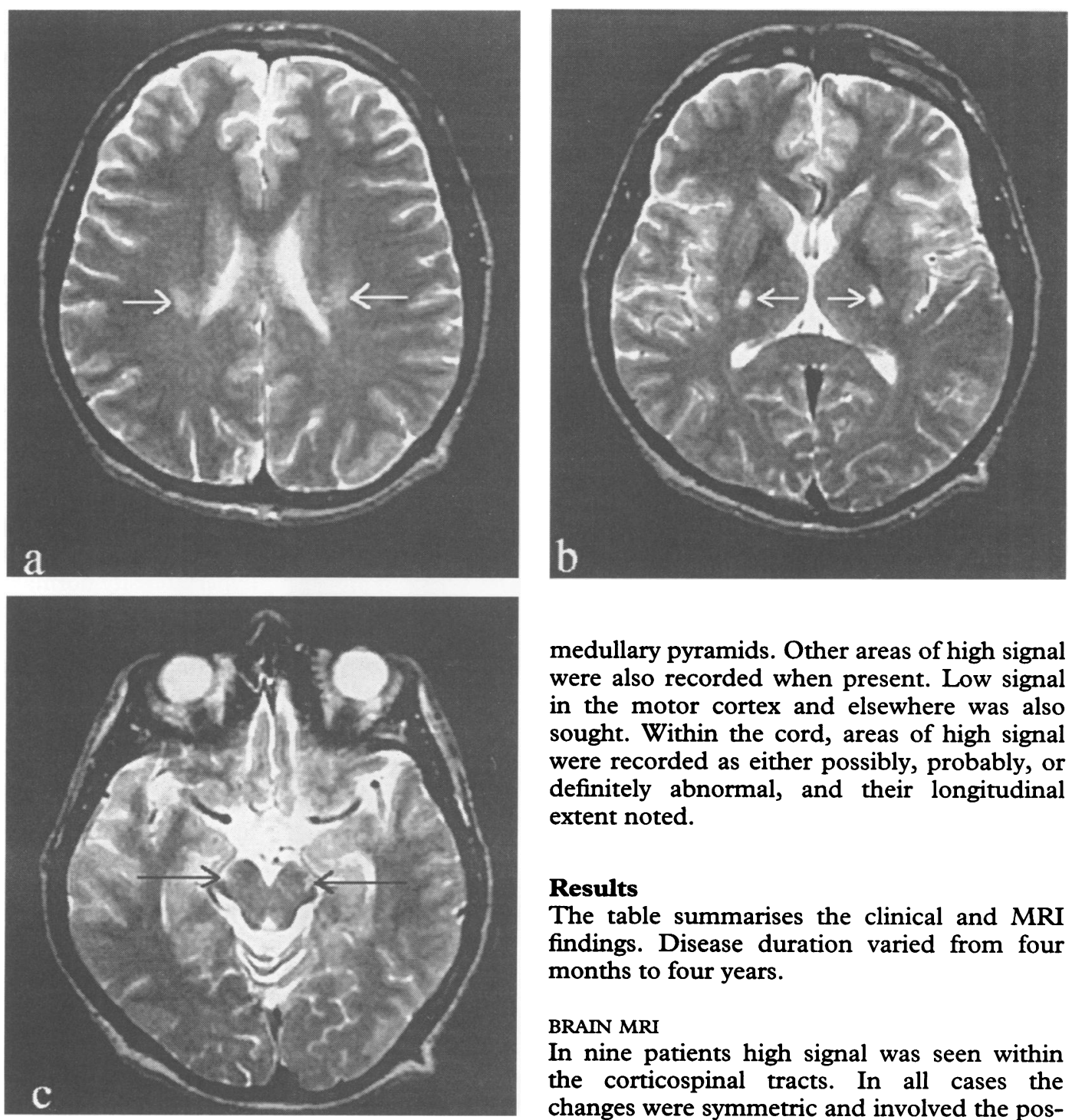

and six (four men and two women, aged 31 to 61 , mean 46 years) axial GE imaging of the cervical cord.

All images were reviewed by one of us (IM), without reference to the clinical features. Patients and controls were intermingled. Areas of increased signal within the corticospinal tracts of the brain were recorded as either absent, mild, or marked in the following areas: motor cortex, centrum semiovale, internal capsules, cerebral peduncles, pons, and

medullary pyramids. Other areas of high signal were also recorded when present. Low signal in the motor cortex and elsewhere was also sought. Within the cord, areas of high signal were recorded as either possibly, probably, or definitely abnormal, and their longitudinal extent noted.

\section{Results}

The table summarises the clinical and MRI findings. Disease duration varied from four months to four years.

BRAIN MRI

In nine patients high signal was seen within the corticospinal tracts. In all cases the changes were symmetric and involved the pos- 
Figure 2 Patient 8: axial T2 weighted SE image of the brain showing low signal in the motor cortex (arrowed).

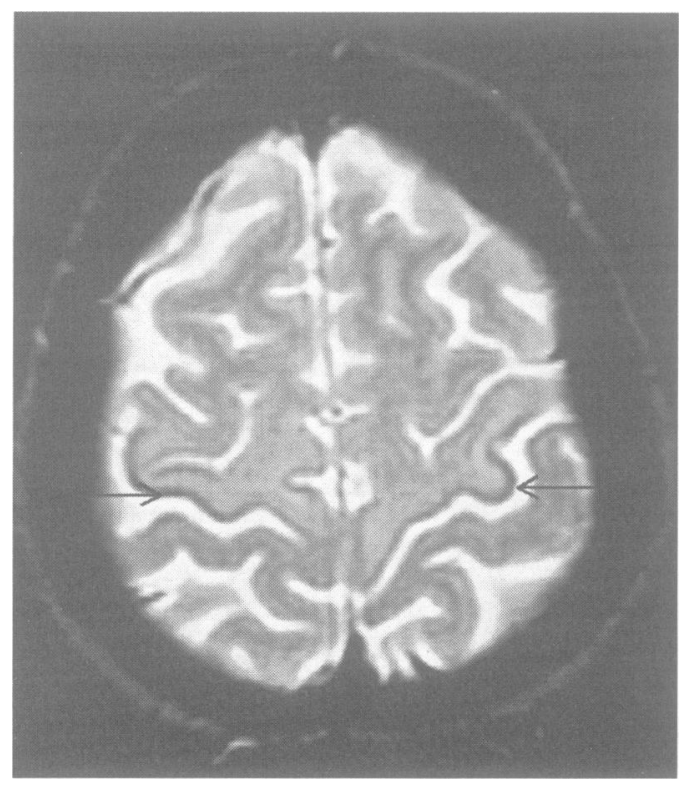

terior limbs of the internal capsule, with rostral or caudal extension in seven (fig 1a-c). One patient (aged 58 years) had quite widespread white matter lesions, compatible with vascular disease.

The FLAIR images were unequivocally abnormal only in patients in whom there were obvious abnormalities on FSE.

Ten patients exhibited low signal in the precentral gyrus; in three of these the postcentral gyrus was also involved. In only one patient (affecting the precentral gyrus only) was the signal change pronounced (fig 2 ).

In four controls there was mild high signal within the posterior limbs of the internal capsule. There was very faint rostral or caudal extension in two. Five controls showed a mild degree of decreased signal in the cortex. This was localised to the precentral gyrus alone in two and the postcentral gyrus in one.

High signal within the cortex $(P=0.05$, Fisher's exact test), centrum semiovale $(P=$

Figure 3 Patient 2: axial $T 2 *$ weighted $G E$ image of the cervical cord showing high signal within the lateral corticospinal tracts (arrowed), more marked on the left.

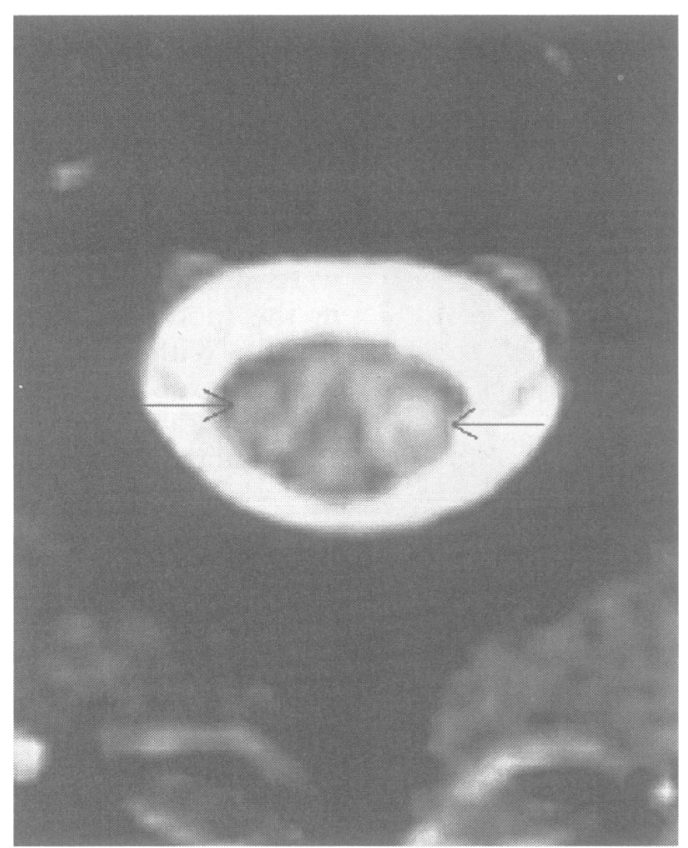

$0.01)$, internal capsules $(P=0.04)$, and cerebral peduncles $(P=0.02)$ was significantly more common in patients than in controls. Low signal affecting the precentral gyrus only was more common in patients than in controls $(P=0.04)$.

\section{SPINAL CORD MRI}

Sagittal T1 and T2 weighted images of the cord were normal in all cases. In eight patients, axial images disclosed definite or probable high signal within the cervical cord. In all cases the abnormal high signal was symmetrically situated in the lateral parts of the spinal cord (fig 3). In five cases the signal change was seen throughout the cervical cord. In one patient imaging of the thoracic cord also showed signal change in the lateral columns.

Two controls showed a possible area of high signal on one axial slice only. In both cases the changes were unilateral. Probable or definite abnormalities were not seen in controls.

\section{Discussion}

We have shown that, using conventional T2 weighted MRI, abnormalities can often be shown in both the brain and spinal cord in patients with motor neuron disease. The signal change closely followed the course of the pyramidal pathways from cortex to spinal cord; the localisation agreed well with the sites of degeneration found in previous histopathological studies. $^{9-12} \mathrm{We}$ therefore agree with other investigators that the MRI changes represent degeneration within the pyramidal pathways. ${ }^{1247}$ As others have found, ${ }^{3}$ we often noticed isolated slight high signal within the posterior limbs of the internal capsules in controls. This finding in isolation must be interpreted cautiously.

The FLAIR sequence did not provide additional useful information and indeed in the context of suspected motor neuron disease may be difficult to interpret, as increased signal within the pyramidal tracts is a normal finding on these images. ${ }^{15}$ In the current study, we found the FLAIR images only to be unequivocally abnormal (beyond the range of hyperintensity normally seen) in those patients in whom there were pronounced abnormalities on conventional T2 weighted images.

Care must also be applied to the interpretation of low signal within the cortical gyri. Ishikawa et $a l^{5}$ found low signal within the motor cortex in three of seven patients with motor neuron disease. We found some degree of low signal in nearly all our patients, but also in six controls. Low signal localised only to the precentral gyrus seems more specific, as does the finding of pronounced signal decrease. The suggestion that this low signal represents abnormal iron deposition within the degenerating cortex must remain speculative until there is histochemical confirmation. That we found pronounced low signal in only one patient (who had spin echo imaging) may relate to the FSE sequence used in most examinations; SE is more sensitive than FSE to 
magnetic field inhomogeneity, such as is caused by the presence of iron.

Although the three patients who had the most pronounced signal change within the cord also had pronounced abnormalities in the brain, in two cases abnormal high signal was found in the cord only. Spinal MRI therefore improved the sensitivity with which abnormalities were detected; corticospinal tract abnormalities in the spinal cord, brain, or both were seen in all patients.

There was no clear relation between the extent of the abnormalities on MRI and the course of the disease, although two of the four patients with the most extensive changes (patients 2 and 7 ) were young with a rapidly progressive course and one of the two patients with the mildest involvement seen on MRI (patient 5) was still only mildly disabled after over four years. No features on MRI helped to distinguish the two patients with purely upper motor neuron syndromes. The present results suggest a useful diagnostic role for MRI in patients with suspected motor neuron disease, but further work is required to establish whether the abnormalities seen on MRI are prognostically important.

1 Goodin DS, Rowley HA, Olney RK. Magnetic resonance imaging in amyotrophic lateral sclerosis. Ann Neurol 1988;23:418-20.
2 Sales Luís ML, Hormigo A, Maurício C, Alves MM, Serrao R. Magnetic resonance imaging in motor neuron disease. $\boldsymbol{f}$ Neurol 1990;237:471-4.

3 Abe K, Fujimura H, Toyooka K, et al. Single-photon emission computed tomographic investigation of patients with motor neuron disease. Neurology 1993;43:1569-73.

4 Pringle CE, Hudson AJ, Munoz DG, Kiernan JA, Brown WF, Ebers GC. Primary lateral sclerosis. Clinical features, neuropathology and diagnostic criteria. Brain 1992;115:495-520.

5 Ishikawa K, Nagura H, Yokota T, Yamanouchi H. Signal loss in the motor cortex on magnetic resonance images in amyotrophic lateral sclerosis. Ann Neurol 1993;33: in amyot 22 .

6 Friedman DP, Tartaglino LS. Amyotrophic lateral sclerosis: hyperintensity of the corticospinal tracts on MR images of the spinal cord. AfR Am $\mathcal{F}$ Roentgenol 1993; 160:604-6.

7 Marti-Fàbregas J, Pujol J. Selective involvement of the pyramidal tract on magnetic resonance imaging in primary lateral sclerosis. Neurology 1990;40:1799-800.

8 Iwasaki Y, Ikeda K, Kinoshita M. MRI lesions in motor neuron disease. $\mathcal{F}$ Neurol 1992;239:112-3.

9 Davison C. Amyotrophic lateral sclerosis. Origin and extent of upper motor neuron lesion. Arch Neurol Psych 1941;46:1039-56.

10 Lawyer T, Netsky MG. Amyotrophic lateral sclerosis. A clinicoanatomic study of fifty-three cases. Arch Neurol Psych 1953;69:171-92.

11 Smith MC. Nerve fibre degeneration in the brain in amyotrophic lateral sclerosis. $\mathcal{F}$ Neurol Neurosurg Psychiatry 1960;23:269-82.

12 Brownell B, Oppenheimer DR, Hughes TJ. The central nervous system in motor neurone disease. $\mathcal{f}$ Neurol Neurosurg Psychiatry 1970;33:338-57.

13 Mirowitz S, Sartor K, Gado M, Torack R. Focal signalintensity variations in the posterior internal capsule: nor$\mathrm{mal}$ MR findings and distinction from pathologic findings. Radiology 1989;172:535-9.

14 Oberwittler C, Ludolf AC, Masur H, Fahrendorf G. MRI in ALS [letter]. Neurology 1992;42:1641.

15 Hajnal JV, De Coene B, Lewis PD, et al. High signal regions in normal white matter shown by heavily T2weighted CSF nulled IR sequences. f Comput Assist Tomogr 1992;16:506-13. 